\title{
Negative chronotropic and inotropic effects of lubiprostone on iPS cell-derived cardiomyocytes via activation of CFTR
}

\author{
Hiraku Akita ${ }^{1}$, Susumu Yoshie ${ }^{2}$, Takafumi Ishida ${ }^{1}$, Yasuchika Takeishi ${ }^{1}$ and Akihiro Hazama ${ }^{2 *}$
}

\begin{abstract}
Background: Lubiprostone (LBP) is a novel chloride channel opener that has been reported to activate chloride channel protein 2 (CIC-2) and cystic fibrosis transmembrane conductance regulator (CFTR). LBP facilitates fluid secretion by activating CFTR in the intestine and is used as a drug for treating chronic constipation. While CIC-2 and CFTR expression has been confirmed in cardiomyocytes (CMs), the effect of LBP on CMs has not yet been investigated. Thus, the present study aimed to investigate the effect of LBP on CMs using mouse-induced pluripotent stem (iPS) cell-derived CMs (iPS-CMs).

Methods: We induced mouse iPS cells into CMs through embryoid body (EB) formation. We compared the differentiated cells to CMs isolated from adult and fetal mice using gene expression, spontaneous beating rate, and contraction ratio analyses.

Results: Gene expression analysis revealed that, in the iPS-CMs, the mRNA expression of the undifferentiated cell markers Rex 1 and Nanog decreased, whereas the expression of the unique cardiomyocyte markers cardiac troponin I $(C T n I)$ and cardiac troponin T (CTNT), increased. Immunostaining showed that the localization of cTnl and connexin-43 in the iPS-CMs was similar to that in the primary fetal CMs (FCMs) and adult CMs (ACMs). LBP decreased the spontaneous beating rate of the iPS-CMs and FCMs, and decreased the contraction ratio of the iPS-CMs and ACMs. The reduction in the beating rate and contraction ratio caused by LBP was inhibited by glycine hydrazide (GlyH), which is a CFTR inhibitor.

Conclusion: These results suggest that LBP stimulates CFTR in CMs and that LBP has negative chronotropic and inotropic effects on CMs. LBP may be useful for treating cardiac diseases such as heart failure, ischemia, and arrhythmia.
\end{abstract}

Keywords: iPS cells, iPS-CMs, Lubiprostone, ClC-2, CFTR

\section{Background}

Lubiprostone (LBP) is an activator of the chloride channel protein $2(\mathrm{ClC}-2)$ and cystic fibrosis transmembrane conductance regulator (CFTR) channels. In the intestinal epithelium, LBP promotes intracellular $\mathrm{Cl}^{-}$and fluid secretion to the intestinal tract through the activation of CFTR due to prostanoid receptor signaling; therefore,

\footnotetext{
* Correspondence: hazama@fmu.ac.jp

${ }^{2}$ Department of Cellular and Integrative Physiology, School of Medicine, Fukushima Medical University, 1 Hikarigaoka, Fukushima City 960-1295, Japan Full list of author information is available at the end of the article
}

LBP is used as a chronic constipation drug [1]. In murine nasal airway epithelia, LBP independently activates both $\mathrm{ClC}-2$ and CFTR [2, 3]. Furthermore, LBP has been reported to increase the contraction of smooth muscle through the prostaglandin E receptor 1 signaling pathway in the small intestine [4]; however, the effect of LBP on cardiomyocytes (CMs) has not yet been determined.

Cation channels, such as sodium, potassium, and calcium channels in CMs have been well studied, and antiarrhythmic or cardiotonic drugs have been developed that modulate these channel activities [5-7]. Although 
the function and role of anion channels have also been investigated in CMs using knockout mice, the function and role of chloride channels have not been as extensively investigated as those of other anion channels. For example, it has been previously reported that the role of the $\mathrm{ClC}-2$ channel is to control the activation of cardiac pacemaker and heart rate under pathological conditions [8]. Additionally, it is well known that CFTR, which is also a $\mathrm{Cl}^{-}$channel, is expressed in CMs and involved in cystic fibrosis. A previous study reported that the infarct size induced by ischemia/reperfusion injury of the heart in CFTR knockout mice was larger than that in wildtype mice, and that the cause was loss of cell volume regulation due to CFTR dysfunction [9]. However, the role of ClC-2 and CFTR in CMs has not yet been fully elucidated, since it is difficult to create, purchase, and reproduce genetically manipulated mice such as knockout mice.

iPS cells can be reprogrammed by the effect of several stemness factors, such as Oct3/4, Nanog, Sox2, Klf4, cMyc, and Lin28 [10-12], and have the ability of selfrenewal and pluripotency. Thus, they are similar to embryonic stem (ES) cells, which are isolated from the inner cell mass of a blastocyst [13, 14]. ES cells can be created by destroying the early embryo, and raise ethical issues. Furthermore, cells differentiated from ES cells may cause rejection after cell transplantation. Therefore, the use of iPS cells generated from individual somatic cells can overcome the disadvantages of using ES cells; iPS cells are also expected to be used as powerful tools for regenerative medicine to repair damaged tissues [11]. Furthermore, genomic integration-free iPS cells produced using episomal vectors [15], Sendai viruses [16], or the piggyBac system [17] are regarded as safer because they avoid the risk of tumor formation. iPS cells can be differentiated into various cell types under the appropriate conditions, and CMs differentiated from iPS cells are effective tools not only for cell and tissue replacement, but also for pharmacological and toxicological testing. The use of self-derived iPS cells also does not cause differences in drug effects among individuals due to genetic single nucleotide polymorphisms (SNPs). For these reasons, iPS-CMs are considered to be an effective source of cells for studying the effects of LBP on $\mathrm{CMs}$ and the roles of $\mathrm{ClC}-2$ and CFTR. However, to accurately demonstrate the effects of LBP on CMs using mouse iPS-CMs, iPS-CMs must be compared with primary CMs isolated from mouse hearts. Many researchers have reported that the characteristics of cells differentiated from mouse iPS cells are similar to those of primary cultured cells isolated from mice, and they have evaluated the pharmacological action of drugs on both types of cells [18-23]. For example, Kuzmenkin et al. reported that CMs generated from mouse iPS cells have the same functional properties as in vivo CMs. In their study, mouse iPS cells were differentiated into CMs in vitro and compared with primary CMs isolated from mouse hearts using immunocytochemistry, electrophysiology, and drug response. The characteristics of the iPSCMs were similar to those of the primary CMs, and the response of the iPS-CMs treated with several drugs, such as the $\mathrm{Na}^{+}$channel blocker lidocaine and the $\mathrm{Ca}^{2+}$ channel blocker nifedipine, was comparable to that of the primary CMs [18]. Sancho-Bru et al. induced mouse iPS cells into hepatocytes and examined the gene expression and functional characteristics of mouse iPS cell-derived hepatocytes by comparing them with those of primary hepatocytes isolated from mouse livers [20]. Yoshie et al. investigated whether mouse iPS cell-derived airway epithelial cells have the characteristics of native airway epithelial cells by comparing their ciliary beating frequency with that of native airway epithelial cells isolated from mouse airways [22].

The aim of the current study was to examine the effect of LBP on CMs using mouse iPS-CMs and CMs isolated from fetal and adult mouse hearts.

\section{Methods}

\section{Animals}

The present study was performed following the approval of the Animal Care and Use Committee in accordance with the Guidelines for Animal Experiments of Fukushima Medical University (Approval No. 30052). Nine- to 12-week-old C57BL/6 J mice (25-28 g) (CLEA Japan, Tokyo, Japan) and BALB/cAJc1 mice (CLEA Japan) that had been pregnant for 17 days $(29-34 \mathrm{~g})$ were used in this study. There were 12 mice in each group. The mice had free access to food and water and were maintained in a temperature- $\left(24-25^{\circ} \mathrm{C}\right)$ and humidity- $(50 \%)$ controlled room. Animals were also subjected to a 12-h light/dark cycle.

\section{Mouse iPS cell culture}

The culture of mouse iPS cells (20D17), carrying Nanog promoter-driven GFP/IRES/puromycin-resistant gene, was performed as described previously [24]. Briefly, mouse iPS cells were cultured on mouse primary embryonic fibroblast feeder cells (KBL9284400, Oriental Yeast Co. Ltd., Tokyo, Japan) in Dulbecco's Modified Eagle Medium (DMEM; FUJIFILM Wako Pure Chemical Corporation, Osaka, Japan) containing 15\% fetal bovine serum (FBS; Thermo Fisher Scientific Inc., Waltham, MA, USA), $2 \mathrm{mML-glutamine} \mathrm{(FUJIFILM} \mathrm{Wako} \mathrm{Pure}$ Chemical Corporation), $100 \mu \mathrm{M}$ non-essential amino acids (FUJIFILM Wako Pure Chemical Corporation), $100 \mu \mathrm{M}$ 2-mercaptoethanol (2-ME; Thermo Fisher Scientific), $10^{3}$ units $/ \mathrm{mL}$ of leukemia inhibitory factor (FUJIFILM Wako Pure Chemical Corporation), and 
penicillin-streptomycin (FUJIFILM Wako Pure Chemical Corporation).

\section{Generation of CMs from iPS cells}

Differentiation of CMs from mouse iPS cells was performed as previously described [25]. Mouse iPS cells were treated with $0.25 \%$ trypsin (FUJIFILM Wako Pure Chemical Corporation) and dispersed into a single-cell suspension in embryoid body (EB) medium, which consisted of knockout DMEM (Thermo Fisher Scientific), $20 \%$ FBS, $2 \mathrm{mM}$ L-glutamine, $100 \mu \mathrm{M}$ non-essential amino acids, $100 \mu \mathrm{M} 2$-ME, and penicillin-streptomycin. Next, the cells were cultured in a 24-well plate to allow EB formation using the hanging drop method. After 5 days, the formed EBs were transferred to a gelatincoated 24-well plate (Greiner Bio-One Co. Ltd., Tokyo, Japan) and cultured in EB medium. The EB medium was exchanged every 2 days.

\section{Reverse transcription polymerase chain reaction}

Total RNA was isolated using an RNeasy Mini kit (Qiagen, Hilden, Germany) according to the manufacturer's protocol. For cDNA synthesis, Superscript Reverse Transcriptase (TaKaRa Bio Inc., Shiga, Japan) was used, and PCR was performed using Ex Taq (TaKaRa Bio Inc.). The PCR cycling conditions were as follows: 30 or 35 cycles at $94{ }^{\circ} \mathrm{C}$ for $30 \mathrm{~s}$, annealing at the temperatures specified for each primer set for $30 \mathrm{~s} ; 72{ }^{\circ} \mathrm{C}$ for $30 \mathrm{~s}$; and a final cycle at $72{ }^{\circ} \mathrm{C}$ for 7 min. The primer sets and annealing temperatures are shown in Table 1.

\section{Immunocytochemistry}

Mouse iPS-CMs, FCMs, and CMs were immersed in 4\% paraformaldehyde (PFA) for $30 \mathrm{~min}$ at room temperature, and then washed with phosphate buffered saline (PBS). The cells were permeabilized with $0.1 \%$ Triton X-100 for $30 \mathrm{~min}$ and then washed with PBS. The cells were then treated with 4\% Block Ace Powder (DS Pharma Biomedical Co., Ltd., Osaka, Japan) in PBS for $30 \mathrm{~min}$, followed by staining via incubation at $4{ }^{\circ} \mathrm{C}$ overnight with specific antibodies against cardiac troponin I (cTnI) and connexin 43 (Cx43) (Abcam plc., Cambridge, UK). Following this incubation, the cells were incubated with Alexa Fluor 488, 568, and DAPI (Molecular Probes, Eugene, USA). Fluorescent images were captured with a confocal laser scanning microscope A1R (Nikon Instech, Tokyo, Japan).

\section{Isolation and culture of $\mathrm{CMs}$ from adult mouse hearts}

The CMs of adult mice were isolated using the Langendorff-free method, as described in a previous study [26]. The buffers and medium for the isolation and culture of the CMs were also prepared according to the same report. In brief, the mice were euthanized with an anesthetic containing $5 \mathrm{mg} / \mathrm{kg}$ butorphanol, $0.3 \mathrm{mg} / \mathrm{kg}$ medetomidine, and $4 \mathrm{mg} / \mathrm{kg}$ midazolam, after which their chests were opened. EDTA buffer, which consisted of $130 \mathrm{mM} \mathrm{NaCl}, 5 \mathrm{mM} \mathrm{KCl}, 0.5 \mathrm{mM}$ $\mathrm{NaH}_{2} \mathrm{PO}_{4}, 10 \mathrm{mM}$ HEPES, $10 \mathrm{mM}$ glucose, $10 \mathrm{mM}$ BDM, $10 \mathrm{mM}$ taurine, and $5 \mathrm{mM}$ EDTA, was injected into the right ventricle, following which the heart was excised and placed in a $60 \mathrm{~mm}$ dish. EDTA buffer, perfusion buffer $(130 \mathrm{mM} \mathrm{NaCl}, 5 \mathrm{mM} \mathrm{KCl}, 0.5 \mathrm{mM}$ $\mathrm{NaH}_{2} \mathrm{PO}_{4}, 10 \mathrm{mM}$ HEPES, $10 \mathrm{mM}$ glucose, $10 \mathrm{mM}$ BDM, $10 \mathrm{mM}$ taurine, and $1 \mathrm{mM} \mathrm{MgCl}_{2}$ ), and collagenase buffer $(0.5 \mathrm{mM}$ collagenase $2,0.5 \mathrm{mM}$ collagenase 4 , and protease XIV) were continuously injected into the left ventricle, and then the heart tissues were dissociated by gentle pipetting. Next, stop buffer, which consisted of perfusion buffer containing 5\% FBS, was added to the $60 \mathrm{~mm}$ dish, and the cell suspension was transferred to a $50 \mathrm{~mL}$ tube through a $100 \mu \mathrm{m}$ cell strainer. After the dissociated CMs were gradually exposed to calcium, they were plated and

Table 1 Primer sequences for RT-PCR

\begin{tabular}{lllll}
\hline Gene & Accession & Sense primer sequence (5'-3') & Antisense primer sequence (5'-3') & Annealing temperature ${ }^{\circ}$ C] \\
\hline Rex1 & NM_009556 & ACGAGTGGCAGTTCTTCTTGGGA & TATGACTCACTTCCAGGGGGCACT & 65 \\
Nanog & AB903574 & GCTTACAAGGGTCTGCTACT & CCTCAGGACTTGAGAGCTT & 60 \\
GFP & NC_011521 & AGAAGAACGGCATCAAGGTG & CTCGTTGGGGTCTTGCTCA & 65 \\
GATA4 & NC_000080 & GCAGCAGCAGTGAAGAGATG & GCGATGTCTGAGTGACAGGA & 60 \\
CTn I & NC_000073 & CTCCTCTGCCAACTACCGAG & CTCAAACTTITTCTTGCGGC & 60 \\
CTn T & NC_000067 & ATCCCCGATGGA & TTCCCACGAGTTTGGAGAC & 65 \\
CX43 & NC_000076 & TTGACTTCAGCCTCCAAGG & AATGAACAGCACCGACAGC & 65 \\
CFTR & NM_021050 & AGTTCCTGGACAGCTCA & CTAATGGCCTGCTGGAAGAT & 60 \\
CLC2 & NM_009900 & CTTAGAGTGGGAAGAACA & CTCCTTAGGGTGACAATCC & 60 \\
Bactin & NM_007614 & TTCCTTCTTGGGTATGGAAT & GAGCAATGATCTTGATCTTC & 60 \\
\hline
\end{tabular}


cultured on a cell culture dish. The culture medium was changed every 2 days.

\section{Isolation and culture of FCMs from fetal mouse hearts} Isolation of FCMs was performed according to a previous study [27]. Briefly, 17-day pregnant BALB/cAJc1 mice (CLEA Japan) were euthanized by cervical dislocation, and the uterus was isolated. Euthanasia by cervical dislocation has been widely used in animal experiment, since it can cause a fast and painless death and avoid damage to the fetus [27-34]. Furthermore, it does not chemically contaminate tissues. The excised uterus was then washed with PBS containing penicillinstreptomycin, followed by removal of the fetus. The heart was removed from the fetus, washed with PBS, then minced and incubated in PBS containing 0.05\% trypsin for $30 \mathrm{~min}$ at $37{ }^{\circ} \mathrm{C}$. The digested heart tissue was homogenized by vortexing and then placed into a $15 \mathrm{~mL}$ tube containing culture medium, which consisted of DMEM with $10 \%$ FBS and penicillin streptomycin. The $15 \mathrm{~mL}$ tube was centrifuged, and the cell pellet was suspended in culture medium. The cell suspension was then plated and cultured on a cell culture dish, and the culture medium was changed every 2 days.

\section{Analysis of beating rate}

The beating rates of the iPS-CMs and FCMs were analyzed using several chemical compounds. Isoproterenol ISP (ISP) $(0.4,4,40$, and $400 \mathrm{nM}$ ) (Tokyo Chemical Industry Co., Ltd., Tokyo, Japan), nitrendipine (NDP) $(10 \mu \mathrm{M})$ (Wako), LBP $(0.05,0.5$, and $5 \mu \mathrm{M})$ (Toronto Research Chemicals, North York, Canada), glycine hydrazide (GlyH) $(5 \mu \mathrm{M})$ (Santa Cruz Biotechnology, Inc., Heidelberg, Germany), and/or $\mathrm{CdCl}_{2}(10 \mu \mathrm{M})$ (Wako) were added to the culture medium. The iPS-CMs and FCMs treated with these chemical compounds were incubated for $20 \mathrm{~min}$ at $37^{\circ} \mathrm{C}$ in a $5 \% \mathrm{CO}_{2}$ incubator, and beating of the iPS-CMs and FCMs was captured at 16 frames per second using an ORCA-ER EMCCD camera (Hamamatsu Photonics K.K., Shizuoka, Japan) connected to an IX-71 microscope (Olympus Corporation, Tokyo, Japan). Changes in beats per minute (bpm) were then analyzed.

\section{Analysis of the contraction ratio}

The ACMs treated with ISP, LBP, GlyH, or $\mathrm{CdCl}_{2}$ were stimulated with monophasic pulses at 2 to $5 \mathrm{~V} / \mathrm{cm}$ and a frequency of $0.5 \mathrm{~Hz}$ with pulse durations of $20 \mathrm{~ms}$ using an electronic stimulator 3F46 (Nippon Avionics Co., Tokyo, Japan). The contraction of iPS-CMs and ACMs was captured at 16 frames per second with an ORCA-ER EMCCD camera connected to an IX-71 microscope. The difference between the relaxation and contraction lengths $(\Delta \mathrm{L})$ of each $\mathrm{iPS}-\mathrm{CM}$ and $\mathrm{ACM}$ was analyzed using ImageJ (US National Institutes of Health, Bethesda, USA) [35], and the ratio of $\Delta \mathrm{L}$ to relaxation length was analyzed to determine the contraction ratio.

\section{Statistical analysis}

All statistical analyses were performed with EZR (Saitama Medical Center, Jichi Medical University, Saitama, Japan), which is a graphical user interface for $\mathrm{R}$ (The R Foundation for Statistical Computing, Vienna, Austria) [36]. All experiments were performed independently at least five times. Data are expressed as the mean \pm SD. All statistical significance was verified using ANOVA and Wilcoxon signed-rank sum tests. $P$ values of $<0.05$ were considered statistically significant.

\section{Results}

Analysis of the iPS-CMs characteristics

We induced iPS cells into CMs through EB formation (Fig. 1a). To confirm the state of the iPS-CMs, a NanogGFP reporter system was used as an efficient marker to mimic endogenous Nanog gene expression. Undifferentiated iPS cells showed GFP expression, which is controlled by the Nanog promoter; however, GFP expression was not observed in the beating region of iPS-CMs (Fig. 1b). We further investigated whether the expression of cardiomyocyte markers could be detected in iPS-CMs. The CM-specific markers GATA4, cTnI, cardiac troponin $\mathrm{T}(c T n T)$, and $C \times 43$ were expressed in iPS-CMs. Additionally, the expression of $\mathrm{ClC}-2$ and CFTR could be detected in iPS-CMs, FCMs, and ACMs. Conversely, the expression of the undifferentiated markers Rex1, Nanog, and GFP was weak in the iPSCMs compared to that in the iPS cells (Fig. 1c). Next, to precisely examine whether iPS-CMs expressed CM markers, these cells were evaluated by double immunostaining. cTnI- and Cx43-positive cells were clearly observed in the iPS-CMs, FCMs, and ACMs (Fig. 1d). These results suggest that iPS-CMs have the characteristics of CMs.

\section{Analysis of iPS-CMs and FCMs beating after LBP treatment}

First, CMs were evaluated for their responses to NDP, which is a calcium channel blocker, and ISP, which is a $\beta$-adrenergic agonist. However, almost all of the ACMs isolated from the adult hearts did not exhibit spontaneous beating. Therefore, beating analysis was performed using iPS-CMs and FCMs. Spontaneous beating of the iPS-CMs and FCMs treated with $10 \mu \mathrm{M}$ NDP stopped (bpm was 0) (Fig. 2a and c). However, the bpm of the iPS-CMs treated with $400 \mathrm{nM}$ ISP increased from $78.0 \pm$ 34.3 to $120 \pm 45.2$ (Fig. 2b). Additionally, the bpm of the FCMs treated with $400 \mathrm{nM}$ ISP increased from $123 \pm$ 19.7 to $141 \pm 22.4$ (Fig. 2d). Next, the effect of LBP on 


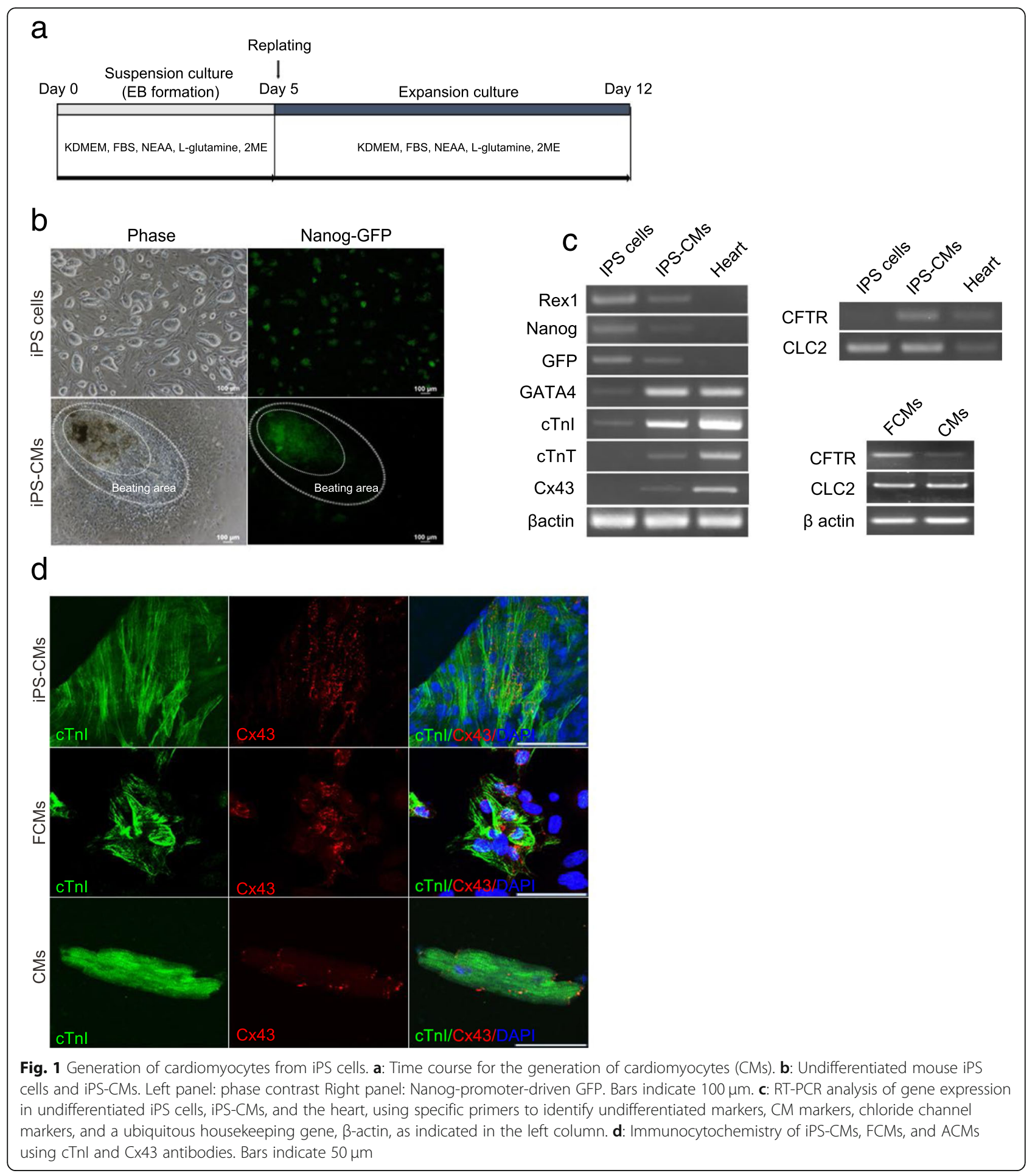

spontaneous beating was examined. The bpm of the iPSCMs treated with $5 \mu \mathrm{M}$ LBP decreased from $48.8 \pm 7.1$ to $34.5 \pm 13.9$ (Fig. 2e). To determine which chloride channels might contribute to the reduction of the beating rate, we examined the beating rate using $\mathrm{CdCl}_{2}$, a ClC-2 channel blocker [37], and GlyH, a CFTR channel blocker [38]. While the bpm of the iPS-CMs treated with $5 \mu \mathrm{M} \mathrm{LBP}$ and $10 \mu \mathrm{M} \mathrm{CdCl}{ }_{2}$ did not change (Fig. 2f), that of the iPS-CMs treated with $5 \mu \mathrm{M}$ LBP and $5 \mu \mathrm{M}$ $\mathrm{GlyH}$ slightly increased from $28.8 \pm 11.6$ to $35.8 \pm 8.7$ (Fig. 2g). When the FCMs were also treated with the same chemical compounds, the changes in bpm were 


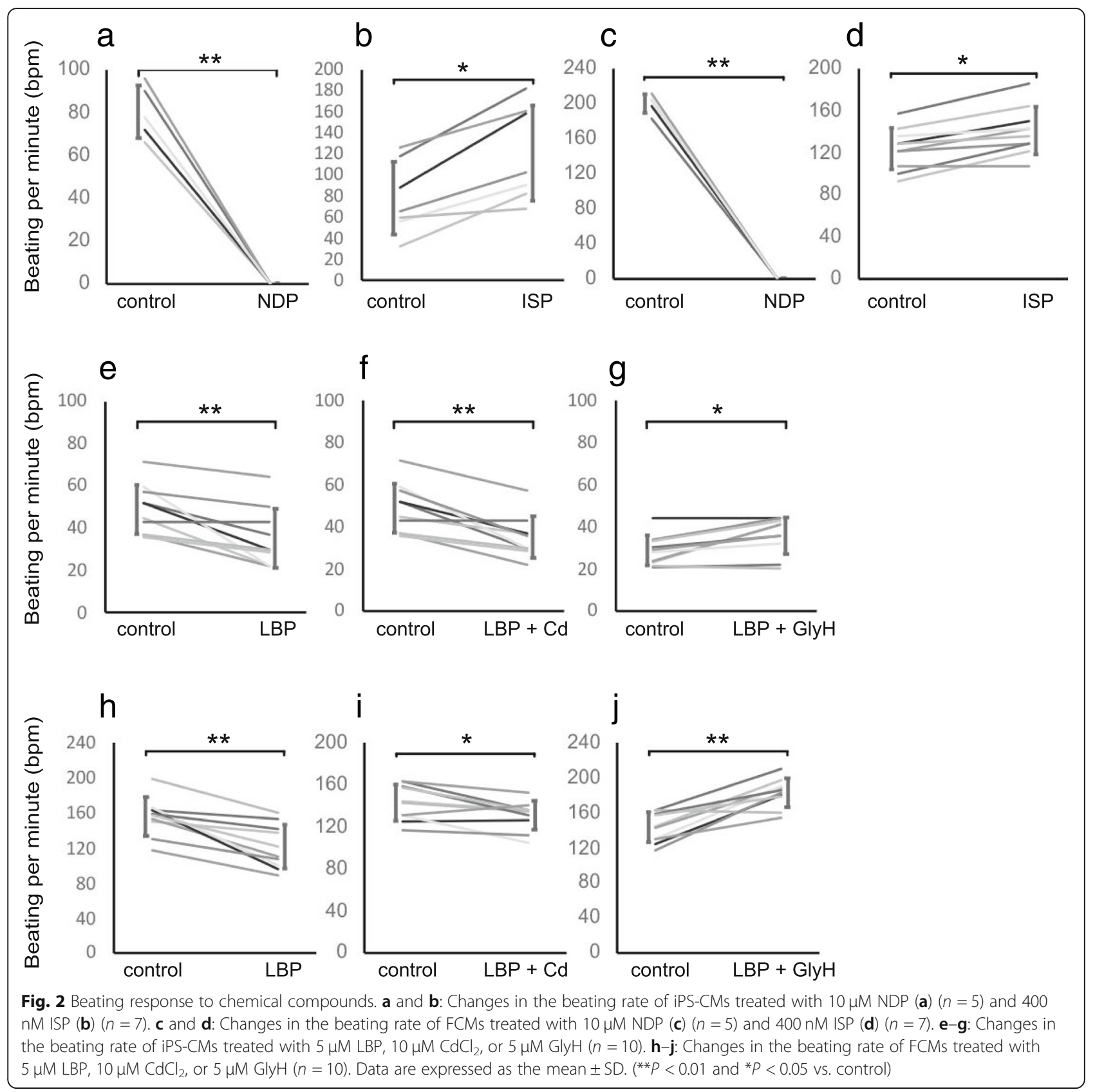

similar to those of the iPS-CMs (Fig. 2h-j). These results indicate that LBP decreased bpm not through the $\mathrm{ClC}-2$ channel, but through CFTR.

\section{Contraction analysis of iPS-CMs and ACMs after LBP treatment}

The contraction of iPS-CMs and ACMs was investigated. Since FCMs tightly adhere to the cell culture dish, their relaxation and contraction lengths could not be accurately measured. First, the contraction ratio of the iPS-CMs treated with ISP at various concentrations was investigated. The contraction ratio of the iPS-CMs significantly increased in the presence of $4 \mathrm{nM}$ or $40 \mathrm{nM}$ ISP (Fig. 3a). Similarly, the contraction rate of the ACMs treated with 4 $\mathrm{nM}$ or $40 \mathrm{nM}$ ISP was higher, but decreased at $400 \mathrm{nM}$ ISP (Fig. 3b). Next, the effect of LBP on the contraction ratio was examined. The contraction ratio of the iPS-CMs and ACMs treated with $5 \mu \mathrm{M}$ LBP significantly decreased compared to that of the control (Fig. $3 \mathrm{c}$ and d). We found that $\mathrm{CdCl}_{2}$ did not inhibit the contraction ratio of the iPS-CMs and ACMs treated with LBP (Fig. 3e), although GlyH did inhibit the reduction in the contraction ratio (Fig. 3f). These results indicate that LBP decreased the contraction ratio not through the ClC-2 channel, but through CFTR (Fig. 4). 

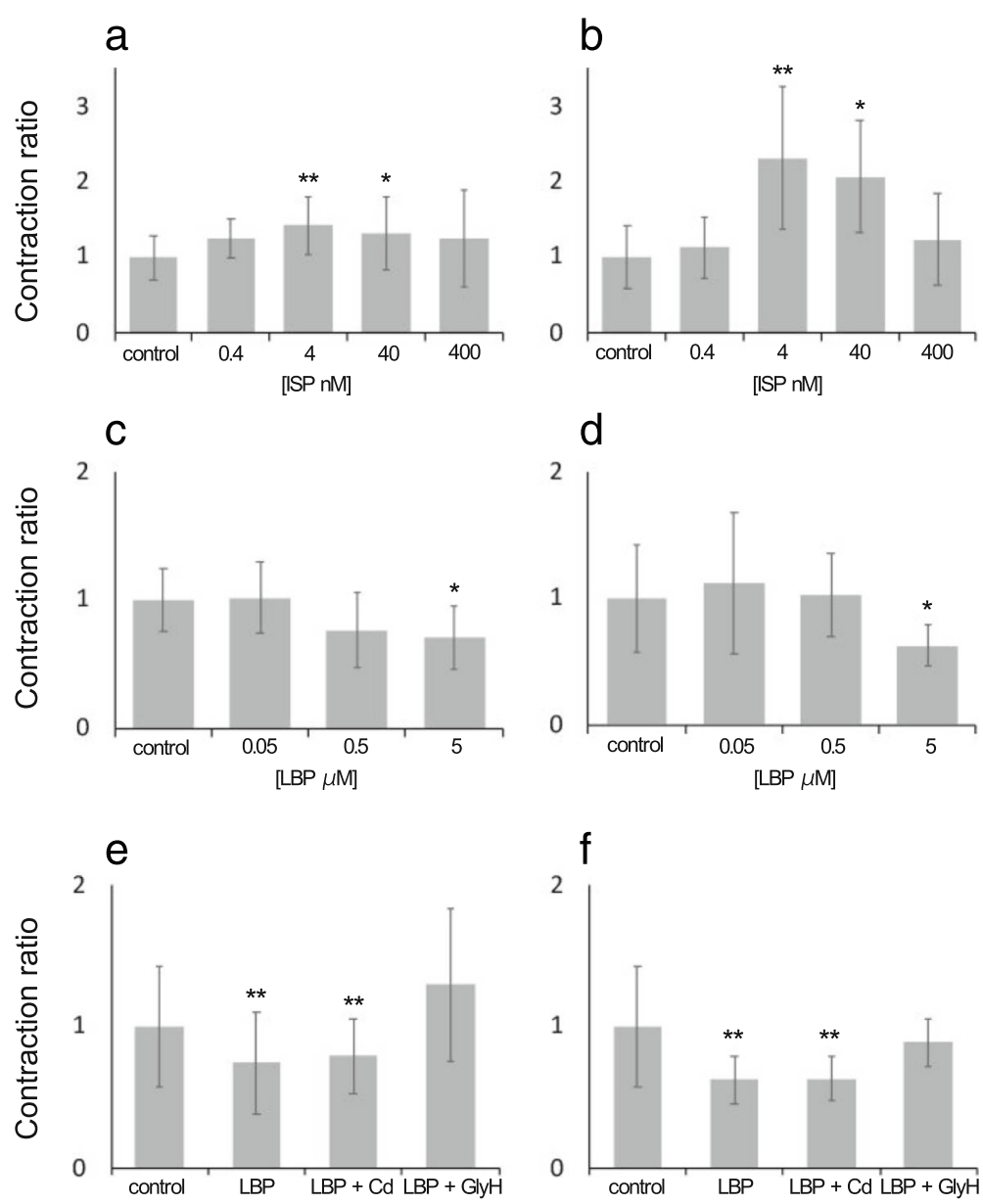

Fig. 3 Contraction response to chemical compounds. $\mathbf{a}$ and $\mathbf{b}$ : Changes in the contraction ratio of iPS-CMs (a) and ACMs (b) treated with ISP at various concentrations. $\mathbf{c}$ and $\mathbf{d}$ : Changes in the contraction ratio of $\mathrm{PSS}-\mathrm{CMs}(\mathbf{c})$ and ACMs (d) treated with various concentrations of LBP. e and $\mathbf{f}$ : Changes in the contraction ratio of iPS-CMs (e) and ACMs (f) treated with $5 \mu \mathrm{M} \mathrm{LBP}, 10 \mu \mathrm{M} \mathrm{CdCl}$, or $5 \mu \mathrm{M} \mathrm{GlyH}$. Data are expressed as the mean \pm SD. $\left(n=10,{ }^{*} P<0.01\right.$ and ${ }^{*} P<0.05$ vs. control)

\section{Discussion}

In the present study, we demonstrated that LBP decreased the beating rate and contraction ratio of iPSCMs, FCMs, and ACMs through CFTR, but not CIC-2. While several research groups have reported that LBP activates CFTR and $\mathrm{ClC}-2$ in the intestinal and nasal airway epithelium [1-3], there have been no studies on the roles of LBP in CMs. To the best of our knowledge, the present study is the first to focus on the effect of LBP on CMs.

First, we induced iPS cells into CMs according to a previously-described simple protocol [25]. GATA4 is expressed in the early fetal heart, and is known to regulate the expression of several genes, such as atrial natriuretic peptide, brain-type natriuretic peptide, and $\alpha$-type myosin heavy chain $[39,40]$. Thus, GATA4 is an important factor in cardiac development, and is a specific marker of CM differentiation [41]. Additionally, cTnI and $\mathrm{cTnT}$, which are present in myocardial fibers, are components of the troponin complex, and they control the contraction of CMs in response to changes in calcium ion concentration. Moreover, gap junctions formed from the connexin family have the function of synchronizing cardiac contraction with adjacent CMs. Cx43, which is a member of the connexin family, is the major protein expressed in the mammalian heart [42]. These markers are often used to evaluate the differentiation of CMs from iPS cells [43-46]. Therefore, we examined the expression of GATA4, cTnI, $c T n T$, and Cx43 mRNA by RT-PCR and the expression of the corresponding proteins by immunostaining. The expression of these genes could be successfully detected in the iPS-CMs, and the cTnI and Cx43 proteins were localized to the appropriate region (Fig. 1c and $\mathrm{d}$ ). These results indicate that iPS-CMs have the characteristics of native CMs.

The calcium channel blocker NDP inhibits increases in intracellular calcium concentration. ISP stimulates $\beta$ adrenergic receptors on $\mathrm{CMs}$ and increases the beating 


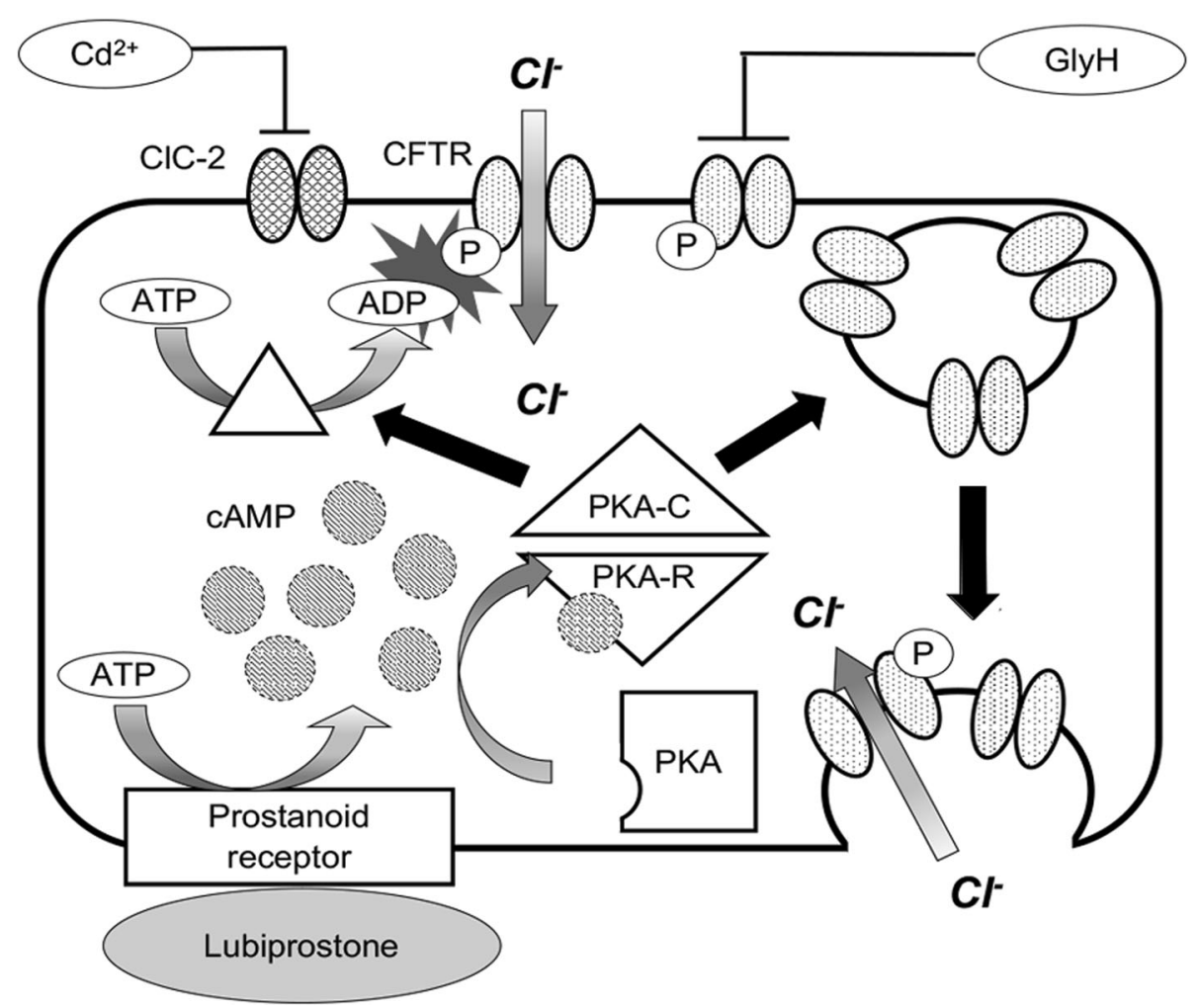

Fig. 4 Mechanisms of lubiprostone action on iPS-CMs. Lubiprostone decreased the beating rate and contraction ratio of iPS-CMs due to the activation of CFTR and the increase in CFTR protein at the plasma membrane though prostanoid receptor signaling

rate due to the increase in intracellular cyclic adenosine monophosphate (cAMP) and calcium ion concentration $[47,48]$. Therefore, we analyzed whether iPS-CMs respond to these chemical compounds. NDP suppressed the beating of iPS-CMs, and ISP increased the beating rate (Fig. $2 \mathrm{a}$ and $\mathrm{b}$ ). It has been reported that ISP increases not only the beating rate but also the contraction force $[47,48]$, and in the current study, the contraction ratio of iPS-CMs treated with ISP was also increased (Fig. 3a). The changes in the beating rate and contraction ratio of the FCMs and ACMs treated with these compounds were also similar to those of the iPS-CMs. The response of CMs treated with these chemical compounds is consistent with that reported in previous studies [49-51]. Therefore, our results indicate that iPS-CMs have the physiological functional characteristics of native CMs.

The beating rate and contraction ratio of iPS-CMs, FCMs, and ACMs decreased with LBP treatment (Figs. 2e, h, 3c, and d). These results are not consistent with those of a previous study [8] that used anti-ClC-2 antibody or ClC-2 knockout mice. The activation of $\mathrm{ClC}-2$ in the heart has been reported to play important roles in the diastolic depolarization and firing of pacemaker cells [8]. However, LBP is known to activate not only ClC-2 but also CFTR in the nasal airway epithelium
$[2,3]$. Thus, we analyzed the beating rate and contraction ratio after treatment with $\mathrm{CdCl}_{2}$ and $\mathrm{GlyH}$ to investigate which chloride channels contributed to the reduction of the beating rate and contraction ratio. The CFTR blocker GlyH inhibited the effect of LBP, while the CLC-2 blocker $\mathrm{CdCl}_{2}$ did not (Figs. $2 \mathrm{~h}-\mathrm{j}$ and $3 \mathrm{e}$ and f); therefore, GlyH acts as an LBP antagonist. It has been reported that the target chloride channel of LBP is dependent on the tissue type. For example, while LBP activates CFTR on the intestinal epithelium [1], it activates both CFTR and $\mathrm{ClC}-2$ on the nasal epithelium [2, $3]$. In the present study, we clarified that LBP activates CFTR in CMs but not ClC-2. In addition, LBP has been reported to increase intracellular cAMP concentration in the intestinal and nasal epithelium. It is well known that an increase in intracellular calcium concentration due to an increase in intracellular cAMP concentration results in an increase in the beating rate and contraction ratio of CMs. However, the results of the current study indicate that the beating rate and contraction ratio of the CMs treated with LBP decreased compared to those of the untreated CMs. On the other hand, LBP has been demonstrated to increase CFTR protein levels at the apical membrane through prostanoid receptor signaling [1, 52]. Thus, we consider that the depolarization and inward $\mathrm{Ca}^{2+}$ currents in LBP-treated CMs were disturbed 
by actively inward flowing $\mathrm{Cl}^{-}$currents mediated by CFTR (Fig. 4). Further investigation is required to elucidate the mechanisms of action of LBP.

\section{Conclusion}

The results of the current study suggest that LBP decreased the beating rate and contraction ratio of iPSCMs by activating CFTR. Since LBP has negative inotropic and chronotropic effects on FCMs and ACMs, iPS-CMs are considered to be an effective cell source for investigating the effects of chemical compounds and channel function. In a future study, we will examine the effect of LBP on human CMs using human iPS-CMs.

\begin{abstract}
Abbreviations
LBP: Lubiprostone; CLC-2: Chloride channel protein 2; CFTR: Cystic fibrosis transmembrane conductance regulator; CMs: Cardiomyocytes; iPS: Induced pluripotent stem; iPS-CMs: IPS cell-derived cardiomyocytes; EB: Embryoid body; CTnl: Cardiac troponin l; CTnT: Cardiac troponin T; FCMs: Fetal cardiomyocytes; ACMs: Adult cardiomyocytes; GlyH: Glycine hydrazide; ES: Embryonic stem; DMEM: Dulbecco's Modified Eagle Medium; FBS: Fetal bovine serum; 2-ME: 2-mercaptoethanol; PBS: Phosphate buffered saline; Cx43: Connexin 43; ISP: Isoproterenol; NDP: Nitrendipine; bpm: Beats per minute
\end{abstract}

\section{Acknowledgements}

We thank Prof. Ikuo Wada (Department of Cell Science, School of Medicine, Fukushima Medical University, Fukushima, Japan) for his technical support, and for allowing us to use the equipment in his department.

\section{Authors' contributions}

$\mathrm{HA}$ and $\mathrm{AH}$ designed the study. HA and SY performed the experiments. The manuscript was written by HA, SY, TI, YT, and AH. All authors have read and approved the final manuscript.

\section{Funding}

This study was supported by Fukushima Medical University. The funder had no role in the design of the study, the collection, analyses, or interpretation of data, writing of the manuscript, or decision to publish the results.

\section{Availability of data and materials}

The datasets used and/or analyzed during the current study are available from the corresponding author upon reasonable request.

\section{Ethics approval and consent to participate}

The present study was carried out following the approval of the Animal Care and Use Committee in accordance with the Guidelines for Animal Experiments of Fukushima Medical University (Approval No. 30052).

\section{Consent for publication}

Not applicable.

\section{Competing interests}

Not applicable.

\section{Author details}

'Department of Cardiovascular Medicine, Fukushima Medical University, Fukushima, Japan. ${ }^{2}$ Department of Cellular and Integrative Physiology, School of Medicine, Fukushima Medical University, 1 Hikarigaoka, Fukushima City 960-1295, Japan.

Received: 10 January 2020 Accepted: 7 April 2020

Published online: 19 April 2020

\section{References}

1. Bijvelds MJC, Bot AGM, Escher JC, de Jonge HR. Activation of intestinal Clsecretion by Lubiprostone requires the cystic fibrosis Transmembrane conductance regulator. Gastroenterology. 2009;137:976-85. https://doi.org/ 10.1053/.j.gastro.2009.05.037.

2. MacDonald KD, McKenzie KR, Henderson MJ, Hawkins CE, Vij N, Zeitlin PL. Lubiprostone activates non-CFTR-dependent respiratory epithelial chloride secretion in cystic fibrosis mice. Am J Physiol Cell Mol Physiol. 2008;295: L933-40.

3. Schiffhauer ES, Vij N, Kovbasnjuk O, Kang PW, Walker D, Lee S, et al. Dual activation of CFTR and CLCN2 by lubiprostone in murine nasal epithelia. Am J Physiol Cell Mol Physiol. 2013;304:L324-31. https://doi.org/10.1152/ajplung. 00277.2012

4. Chan WW, Mashimo H. Lubiprostone increases small intestinal smooth muscle contractions through a prostaglandin E receptor 1 (EP)-mediated pathway. J Neurogastroenterol Motil. 2013;19:312-8. https://doi.org/10.5056/ jnm.2013.19.3.312.

5. Ho W-SV, Davis AJ, Chadha PS, Greenwood IA. Effective contractile response to voltage-gated $\mathrm{Na}+$ channels revealed by a channel activator. Am J Phys Cell Phys. 2013;304:C739-47. https://doi.org/10.1152/ajpcell.00164.2012.

6. Splawski I, Timothy KW, Decher N, Kumar P, Sachse FB, Beggs AH, et al. Severe arrhythmia disorder caused by cardiac L-type calcium channel mutations. Proc Natl Acad Sci U S A. 2005;102:8089-96. https://doi.org/10. 1073/pnas.0502506102.

7. Zimmer T. Effects of tetrodotoxin on the mammalian cardiovascular system. Mar Drugs. 2010;8:741-62. https://doi.org/10.3390/md8030741.

8. Huang ZM, Prasad C, Britton FC, Ye LL, Hatton WJ, Duan D. Functional role of CLC-2 chloride inward rectifier channels in cardiac sinoatrial nodal pacemaker cells. J Mol Cell Cardiol. 2009;47:121-32. https://doi.org/10.1016/j. yjmcc.2009.04.008.

9. Uramoto H, Okada T, Okada Y. Protective role of cardiac CFTR activation upon early reperfusion against myocardial infarction. Cell Physiol Biochem. 2012:30:1023-38.

10. Takahashi K, Yamanaka S. Induction of pluripotent stem cells from mouse embryonic and adult fibroblast cultures by defined factors. Cell. 2006;126: 663-76.

11. Takahashi K, Tanabe K, Ohnuki M, Narita M, Ichisaka T, Tomoda K, et al. Induction of pluripotent stem cells from adult human fibroblasts by defined factors. Cell. 2007:131:861-72.

12. Yu J, Vodyanik MA, Smuga-Otto K, Antosiewicz-Bourget J, Frane JL, Tian S, et al. Induced pluripotent stem cell lines derived from human somatic cells. Science. 2007:318:1917-20.

13. Evans M, Kaufman M. Establishment in culture of pluripotent cells from mouse embryos. Nature. 1981;292:154-6.

14. Thomson J, Itskovitz-Eldor J, Shapiro S, Waknitz M, Swiergiel J, Marshall V, et al. Embryonic stem cell lines derived from human blastocysts. Science. 1998;282:1145-7.

15. Okita K, Matsumura Y, Sato Y, Okada A, Morizane A, Okamoto S, et al. A more efficient method to generate integration-free human iPS cells. Nat Mehods. 2011;8:409-12.

16. Fusaki N, Ban H, Nishiyama A, Saeki K, Hasegawa M. Efficient induction of transgene-free human pluripotent stem cells using a vector based on Sendai virus, an RNA virus that does notintegrate into the host genome. Proc Jpn Acad Ser B Phys Biol Sci. 2009;85:348-62.

17. Woltjen $K$, Michael IP, Mohseni $P$, Desai $R$, Mileikovsky $M$, Hämäläinen $R$, et al. piggyBac transposition reprograms fibroblasts to induced pluripotent stem cells. Nature. 2009;458:766-70.

18. Kuzmenkin A, Liang H, Xu G, Pfannkuche K, Eichhorn H, Fatima A, et al. Functional characterization of cardiomyocytes derived from murine induced pluripotent stem cells in vitro. FASEB J. 2009;23:4168-80.

19. Chan SSK, Li HJ, Hsueh YC, Lee DS, Chen JH, Hwang SM, et al. Fibroblast growth factor-10 promotes cardiomyocyte differentiation from embryonic and induced pluripotent stem cells. PLoS One. 2010;5:e14414.

20. Sancho-Bru P, Roelandt P, Narain N, Pauwelyn K, Notelaers T, Shimizu T, et al. Directed differentiation of murine-induced pluripotent stem cells to functional hepatocyte-like cells. J Hepatol. 2011;54:98-107. https://doi.org/ 10.1016/j.jhep.2010.06.014.

21. Gai H, Nguyen DM, Moon YJ, Aguila JR, Fink LM, Ward DC, et al. Generation of murine hepatic lineage cells from induced pluripotent stem cells. Differentiation. 2010;79:171-81. https://doi.org/10.1016/j.diff.2010.01.002.

22. Yoshie S, Imaizumi M, Nakamura R, Otsuki K, Ikeda M, Nomoto Y, et al, Generation of airway epithelial cells with native characteristics from mouse induced pluripotent stem cells. Cell Tissue Res. 2016;364:319-30. https://doi. org/10.1007/s00441-015-2304-7. 
23. Yoshie S, Omori K, Hazama A. Airway regeneration using iPS cell-derived airway epithelial cells with Cl- channel function. Channels (Austin). 2019;13: 227-34. https://doi.org/10.1080/19336950.2019.1628550.

24. Yoshie S, Nakamura R, Kobayashi D, Miyake M, Omori K, Hazama A. Functional characterization of various channel-expressing central airway epithelial cells from mouse induced pluripotent stem cells. J Cell Physiol. 2019;234:15951-62. https://doi.org/10.1002/jcp.28254

25. Kehat I, Kenyagin-Karsenti D, Snir M, Segev H, Amit M, Gepstein A, et al. Human embryonic stem cells can differentiate into myocytes with structural and functional properties of cardiomyocytes. J Clin Invest. 2001;108:407-14. https://doi.org/10.1172/JCI200112131.

26. Ackers-Johnson M, Li PY, Holmes AP, O'Brien S-M, Pavlovic D, Foo RS. A simplified, Langendorff-free method for concomitant isolation of viable cardiac Myocytes and Nonmyocytes from the adult mouse heart. Circ Res. 2016;119:909-20. https://doi.org/10.1161/CIRCRESAHA.116.309202.

27. Okamura S, Suzuki A, Johkura K, Ogiwara N, Harigaya M, Yokouchi T, et al. Formation of the biopulsatile vascular pump by Cardiomyocyte transplants circumvallating the abdominal aorta. Tissue Eng. 2002;8:201-11.

28. Suzuki R, Miyahara K, Murakami H, Doi T, Lane GJ, Mabuchi Y, et al. Abnormal neural crest innervation in Sox10-Venus mice with all-trans retinoic acidinducedanorectal malformations. Pediatr Surg Int. 2014;30:189-95.

29. Mandasari M, Sawangarun W, Katsube K, Kayamori K, Yamaguchi A, Sakamoto K. A facile one-step strategy for the generation of conditional knockout mice to explore the role of Notch1 in oroesophageal tumorigenesis. Biochem Biophys Res Commun. 2016;469:761-7.

30. Awodele O, Coulidiaty AGV, Afolayan GO, Agagu S, Omoseyindemi B, Busia K. Toxicological evaluation of Picralima nitida in rodents. J Ethnopharmacol. 2019:23:205-19.

31. Wuri $\mathrm{L}, \mathrm{Agca} C$, Agca Y. Euthanasia via $\mathrm{CO}_{2}$ inhalation causes premature cortical granule exocytosis in mouse oocytes and influences in vitro fertilization and embryo development. Mol Reprod Dev. 2019;86:825-34.

32. Zhu S, Yam M, Wang Y, Linton JD, Grenell A, Hurley JB, et al. Impact of euthanasia, dissection and postmortem delay on metabolic profile in mouseretina and RPE/choroid. Exp Eye Res. 2018;174:113-20.

33. Vanderwolf CH, Buzsaki G, Cain DP, Cooley RK, Robertson B. Neocortical and hippocampal electrical activity following decapitation in the rat. Brain Res. 1988;451:340-4.

34. Iwarsson K, Rehbinder C. A study of different euthanasia techniques in Guinea pigs, rats, and mice. Animal response and post-mortem findings. Scand J Lab Anim Sci. 1993;20:191-205.

35. Schneider CA, Rasband WS, Eliceiri KW. NIH image to ImageJ: 25 years of image analysis. Nat Methods. 2012;9:671-5.

36. Kanda Y. Investigation of the freely available easy-to-use software 'EZR' for medical statistics. Bone Marrow Transplant. 2013;48:452-8. https://doi.org/ 10.1038/bmt.2012.244

37. Garcia-Olivares J, Alekov A, Boroumand MR, Begemann B, Hidalgo P, Fahlke C. Gating of human ClC-2 chloride channels and regulation by carboxyterminal domains. J Physiol. 2008;586:5325-36.

38. Muanprasat C, Sonawane ND, Salinas D, Taddei A, Galietta LJV, Verkman AS Discovery of Glycine Hydrazide pore-occluding CFTR inhibitors. J Gen Physiol. 2004;124:125-37. https://doi.org/10.1085/jgp.200409059.

39. Evans T. Regulation of cardiac gene expression by GATA-4/5/6. Trends Cardiovasc Med. 1997;7:75-83. https://doi.org/10.1016/S10501738(97)00010-8.

40. Luu BE, Tessier SN, Duford DL, Storey KB. The regulation of troponin I, C and ANP by GATA4 and Nkx2.5 in heart of hibernating thirteen-lined ground squirrels, Ictidomys tridecemlineatus. PLoS One. 2015;10:e0117747.

41. Monzen K, Shiojima I, Hiroi Y, Kudoh S, Oka T, Takimoto E, et al. Bone Morphogenetic Proteins Induce Cardiomyocyte Differentiation through the Mitogen-Activated Protein Kinase Kinase Kinase TAK1 and Cardiac Transcription Factors Csx/Nkx-2.5 and GATA-4. Mol Cell Biol. 1999;19:7096105. https://doi.org/10.1128/MCB.19.10.7096

42. Beyer EC, Paul DL, Goodenough DA. Connexin43: a protein from rat heart homologous to a gap junction protein from liver. J Cell Biol. 1987;105:26219. https://doi.org/10.1083/jcb.105.6.2621

43. McDermott-Roe C, Lv W, Maximova T, Wada S, Bukowy J, Marquez M, et al. Investigation of a dilated cardiomyopathy-associated variant in BAG3 using genome-edited iPSC-derived cardiomyocytes. JCI Insight. 2019:4:128799.

44. Stoehr A, Kennedy L, Yang Y, Patel S, Lin Y, Linask KL, et al. The ribosomal prolyl-hydroxylase OGFOD1 decreases during cardiac differentiation and modulates translation and splicing. JCI Insight. 2019:5:128496.
45. Wang $H, X i$ Y, Zheng Y, Wang X, Cooney AJ. Generation of electrophysiologically functional cardiomyocytes from mouse induced pluripotent stem cells. Stem Cell Res. 2016;16:522-30.

46. Fatima A, Xu G, Nguemo F, Kuzmenkin A, Burkert K, Hescheler J, et al. Murine transgenic iPS cell line for monitoring and selection of cardiomyocytes. Stem Cell Res. 2016;17:266-72.

47. Kukovetz WR, Pöch G, Wurm A. Effect of catecholamines, histamine and oxyfedrine on isotonic contraction and cyclic AMP in the Guinea-pig heart. Naunyn Schmiedeberg's Arch Pharmacol. 1973;278:403-24. https://doi.org/ 10.1007/BF00501483.

48. Blinks JR. The nature of the antagonism by methoxamine of the chronotropic and inotropic effects of catecholamines. Naunyn Schmiedebergs Arch Exp Pathol Pharmakol. 1964;248:73-84.

49. Wells SP, Waddell HM, Sim CB, Lim SY, Bernasochi GB, Pavlovic D, et al. Cardiomyocyte functional screening: interrogating comparative electrophysiology of high-throughput model cell systems. Am J Phys Cell Phys. 2019;317:C1256-67.

50. Huebsch N, Loskill P, Deveshwar N, Spencer Cl, Judge LM, Mandegar MA, et al. Miniaturized iPS-cell-derived cardiac muscles for physiologically relevant drug response analyses. Sci Rep. 2016;6:24726.

51. Lalevée N, Rebsamen MC, Barrère-Lemaire S, Perrier E, Nargeot J, Bénitah JP, et al. Aldosterone increases T-type calcium channel expression and in vitro beating frequency in neonatal rat cardiomyocytes. Cardiovasc Res. 2005;67: 216-24.

52. Ao M, Venkatasubramanian J, Boonkaewwan C, Ganesan N, Syed A, Benya $\mathrm{RV}$, et al. Lubiprostone activates $\mathrm{Cl}$ - secretion via CAMP signaling and increases membrane CFTR in the human Colon carcinoma cell line, T84. Dig Dis Sci. 2011;56:339-51. https://doi.org/10.1007/s10620-010-1495-8.

\section{Publisher's Note}

Springer Nature remains neutral with regard to jurisdictional claims in published maps and institutional affiliations.

Ready to submit your research? Choose BMC and benefit from:

- fast, convenient online submission

- thorough peer review by experienced researchers in your field

- rapid publication on acceptance

- support for research data, including large and complex data types

- gold Open Access which fosters wider collaboration and increased citations

- maximum visibility for your research: over $100 \mathrm{M}$ website views per year

At $\mathrm{BMC}$, research is always in progress.

Learn more biomedcentral.com/submissions 